\title{
Treatment of an oronasal fistula in a patient on bisphosphonate therapy: A case study
}

\section{Leczenie przetoki ustno-nosowej u pacjenta przyjmującego leki z grupy bisfosfonianów - opis przypadku}

\author{
Piotr Radziszewski, ${ }^{1, A-E}$, Maciej Włodarczyk', ${ }^{1, F}$, Ivan Yafimtsau ${ }^{2, C-E}$ \\ ${ }^{1}$ Maxillofacial Surgery Ward, Regional Specialist Hospital, Radom, Poland \\ ${ }^{2}$ Private practice Miła Clinic, Radom, Poland \\ A - research concept and design; $\mathrm{B}$ - collection and/or assembly of data; $\mathrm{C}$ - data analysis and interpretation; \\ $D$ - writing the article; $E$ - critical revision of the article; $F$ - final approval of the article
}

Address for correspondence

Ivan Yafimtsau

E-mail: ekalinow@gmail.com

Funding sources

None declared

Conflict of interest

None declared

Received on January 30, 2019

Reviewed on October 20, 2019

Accepted on November 13, 2019

Published online on March 9, 2020

Cite as

Radziszewski P, Włodarczyk M, Yafimtsau I.

Treatment of an oronasal fistula in a patient on bisphosphonate therapy: A case study. Dent Med Probl. 2020;57(1):117-123.

doi:10.17219/dmp/114184

DOI

$10.17219 / \mathrm{dmp} / 114184$

Copyright

๑ 2020 by Wroclaw Medical University

This is an article distributed under the terms of the

Creative Commons Attribution 3.0 Unported License (CC BY 3.0)

(https://creativecommons.org/licenses/by/3.0/)

\begin{abstract}
Bisphophonates (BPs) are a group of drugs used in treating bone diseases, which may lead to the development of the osteonecrosis of the jaw (ONJ). The negative impact of BPs on angiogenesis is among the causes of ONJ. The specific mechanisms of complications are unknown. What is taken into consideration is the trauma background, which, in combination with the implemented BP treatment, can induce bone necrosis. One of the possible consequences of necrotic change progression is the development of an oronasal fistula. Treatment generally requires a surgical intervention.

The paper describes the course of treatment of an oronasal fistula in a patient with BP osteitis, currently using an upper denture. The fistula arose a year after the removal of a protruding sequestrum in the region of the hard palate. An attempt was made to treat the fistula by the mobilization of soft tissues from the palate and the bilayered closure of the fistula with the use of a pedicled connective tissue graft on the greater palatine artery, along with a Tinti-Parma-Benfenati (TPB) flap. The patient was subjected to appropriate post-procedural measures. Regular follow-ups did not reveal any abnormalities in the course of healing.

The use of the abovementioned procedure proved to be an effective method of treatment of an oronasal fistula. The use of a pedicled connective tissue graft for the closure of the oronasal fistula caused by BP therapy had a significant effect on the treatment outcome.
\end{abstract}

Key words: bisphosphonates, oronasal fistula, Tinti-Parma-Benfenati flap

Słowa kluczowe: bisfosfoniany, przetoka ustno-nosowa, płat Tinti-Parma-Benfenati 


\section{Introduction}

Drugs from the bisphosphonate (BP) group are nowadays used as the important complementary treatment of bone diseases, ${ }^{1}$ especially in oncology - as the supportive therapy of the main disease. Usually BPs are used as supplemental therapy for breast, prostate and kidney cancer and their metastases, osteoporosis, Paget's disease, hypercalcemia of various etiologies, osteogenesis imperfecta (brittle bone disease) as well as for congenital bone fragility, caused by the mutations of the collagen type I gene. ${ }^{2-8}$ The advantages of BPs are widely known and the drugs are continuously used despite their side effects. According to the Cancer Research UK charity organization, benefits from the use of BPs constitute an overwhelming majority as compared to side effects, described as moderate, and rarely severe. ${ }^{9}$ Therefore, the application of BPs seems to be certain and unwavering.

In addition, BPs are being increasingly used in the treatment of proliferative diseases (e.g., multiple myeloma) and cancerous diseases with metastases to bone tissue (including lung, breast and prostate cancer). ${ }^{10}$

However, the complications caused by chronic BP consumption are becoming a growing problem, the most common being necrosis within the jaw bones and the formation of bone sequestra. ${ }^{10}$

Bisphosphonates, as a group, can be categorized based on multiple criteria, including the presence of a nitrogen atom in the molecule. ${ }^{1,5,6,8}$

Non-nitrogen-containing bisphosphonates (non-N-BPs), such as tiludronate, etidronate and clodronate, are ingested by osteoclasts and block cellular metabolic pathways by releasing a toxic methylene-containing adenosyne triphosphate (ATP) analog; for example, clodronic acid (dichloromethylene bisphosphonate) may be metabolized to a non-hydrolyzable ATP analog - adenosine 5'-(beta, gamma-dichloromethylene) triphosphate - which is likely to block the ATP-using enzymes and induce apoptosis. ${ }^{1,5,7,8}$

Nitrogen-containing bisphosphonates (N-BPs), such as zoledronate, act through a more complex mechanism and block the mevalonate pathway by inhibiting farnesyl pyrophosphate synthetase, leading to the prenylation of small guanosine triphosphate (GTP)-dependent protein molecules (most likely GTPase-activating protein), which are important for the activity and survival of osteoclasts. Consequently, bone resorption ceases, specifically of its mineral matrix, and the production of bone morphogenic proteins (BMPs) and insulin-like growth factor 1 (IGF-1) is decreased, along with the transformation of stem cells into osteoblasts.

The literature on the subject is rich in reports on BPdependent bone necrosis in the craniofacial region. This leads to the isolation of a new medical condition called bisphosphonate-related osteonecrosis of the jaw (BRONJ). ${ }^{11}$

In 2007, bisphosphonate osteonecrosis was defined as an exposed bone fragment that does not heal spontaneously during a time period of 8 weeks and is not the result of radiotherapy. ${ }^{6,12}$
The mechanisms of dead tissue formation in the absence of blood supply are known. The bone is supplied with nutrients by the periosteum. In cases of soft tissue injury (e.g., the use of removable dentures, a surgical intervention involving the dissection or elevation of the periosteum from the compact bone), blood circulation is disturbed. In a healthy organism, repair is quick; local necrosis is a direct stimulator - on the cellular level - for the formation of new vessels and connections on the periosteum-bone border, which leads to tissue regeneration and the restitution of the proper blood supply. Due to the negative influence BPs exert on vasculogenesis, rapid repair and the restoration of vascularity are not observed. For the same reason, simple procedures like tooth extraction can also lead to BRONJ. However, our observations regarding the antiangiogenic action of BPs did not explain the necrosis of the jaws. We would like to emphasize that other antiangiogenic drugs (i.e., thalidomide) did not cause such a complication. ${ }^{13}$

An extremely important factor affecting the effectiveness of BP therapy is the route of administration of the drug. In the case of oral administration, the absorption of the preparation is about $10 \%$, with the remainder being excreted in an unchanged form by the kidneys. If BPs are administered parenterally, their absorption increases to $50 \%$, which significantly affects the process of drug accumulation in bone tissue. $^{8}$

However, the exact mechanism of BRONJ formation is not fully known. The described research methods referring to the evaluation of pharmacological effects on osteoclasts, despite the involvement of many facilities with different degrees of reference, have not elucidated the mechanism of BRONJ yet. The accepted trauma hypothesis is insufficient, as sequestra are also identified beyond the place directly exposed to injury. ${ }^{6,7}$

The treatment of BRONJ within the oral cavity, a site constantly subjected to mechanical injury (mastication, the use of prosthetics) and also of diverse physiological flora, is exceptionally demanding. ${ }^{5-7,11}$

The progression of BRONJ is similar to that of typical osteitis, usually appearing in the mandible, primarily due to poor blood supply as compared to the maxilla..$^{14,15}$

Initially, in the acute inflammation phase, no bone meshwork abnormalities and no X-ray changes are observed. The abovementioned features appear after 10-12 days of the inflammatory process. ${ }^{14}$

$X$-ray imaging shows an increase in bone permeability to X-rays, with the uniform disappearance of the bone or a meshwork resembling mole holes. There may also be areas of denser bone structure within the lesions with an increased permeability to X-rays. They comprise the so-called bone islands that have not undergone resorption and are termed bone sequestra. In the case of chronic bone inflammation, areas of density typical for bone tissue are observed as the surroundings of sites with a decreased tissue density. They arise as the result of the reaction of the 
bone to the inflammatory process, which is characterized by an increased growth of the trabecular meshwork..$^{14,15}$

Surgical treatment includes the removal of dead tissues, while retaining the regions of the bone that exhibit correct clinical appearance. The scope of the procedure determines the appearance of bleeding on the entire surface of the exposed bone surrounding the sequestrum. Often, the outcome is the formation of an oroantral or oronasal fistula. $5,7,11,14,15$

\section{Case report}

The patient, aged 77, with oncological history (prostate cancer treated since 2005, BP therapy from 2005 to 2009, zoledronic acid administered as supplemental therapy), was subjected to the removal of a sequestrum from the region of the hard palate. The patient used a full denture for the upper and lower jaws. The surgery was performed in hospital conditions at the maxillofacial surgery ward in September 2017. After hospitalization, the patient was monitored for 2 months in the clinic, with the purpose of regularly replacing the surgical dressing and wound care. Correct healing, without complaints of pain, was observed during follow-up visits. In February 2018, a clinical examination did not reveal any features of fistulation and the patient did not report oronasal leakage. The patient requested a checkup in September 2018 due to the transfer of fluids from the oral cavity to the nasal cavity. A clinical examination confirmed the separation of the wound margins and the formation of an oronasal fistula (Fig. 1).

The patient was qualified for surgical treatment. Antibiotic protection was implemented for 1 week before the planned procedure (Clindamycin (MIP Pharma Polska Sp. z o.o., Gdańsk, Poland) $600 \mathrm{mg}$ tablet, 1 tablet every $12 \mathrm{~h}$ ), which was continued for 2 weeks after the procedure.

The surgical procedure was performed under local anesthesia using a $2 \%$ solution of lignocaine with norepinephrine in clinic conditions. The described procedure was carried out using an optical magnifying device - a binocular loupe ( $\times 3.3$ magnification). The surgery and healing proceeded without general or local complications.

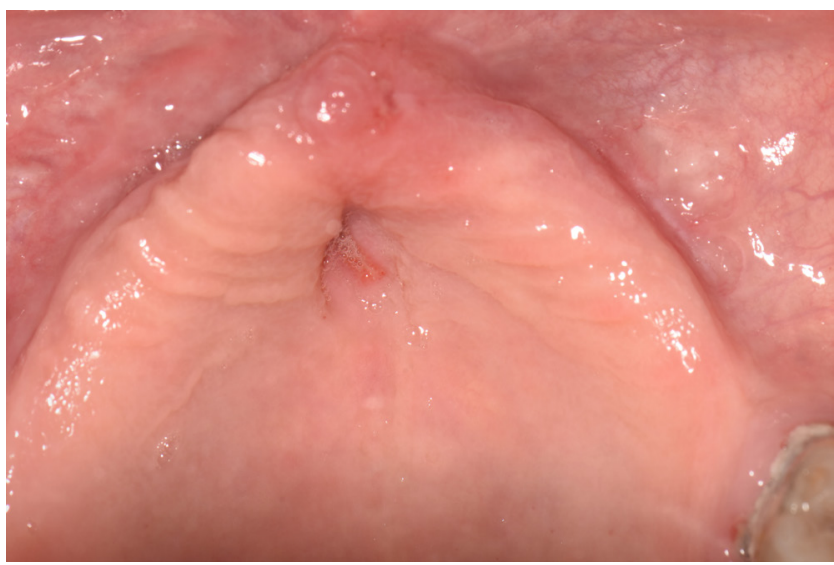

Fig. 1. Status before surgery showing the initial stage

\section{Dissection of the fistula}

After local anesthesia was administered, the preparation of the borders of the oronasal fistula was carried out using the generally accepted methods. The revealed bone tissue was unchanged, vividly bleeding. It was, therefore, decided to limit the preparation of the wound edges to the borders of the epithelial layer of the mucous membrane of the hard palate (Fig. 2).

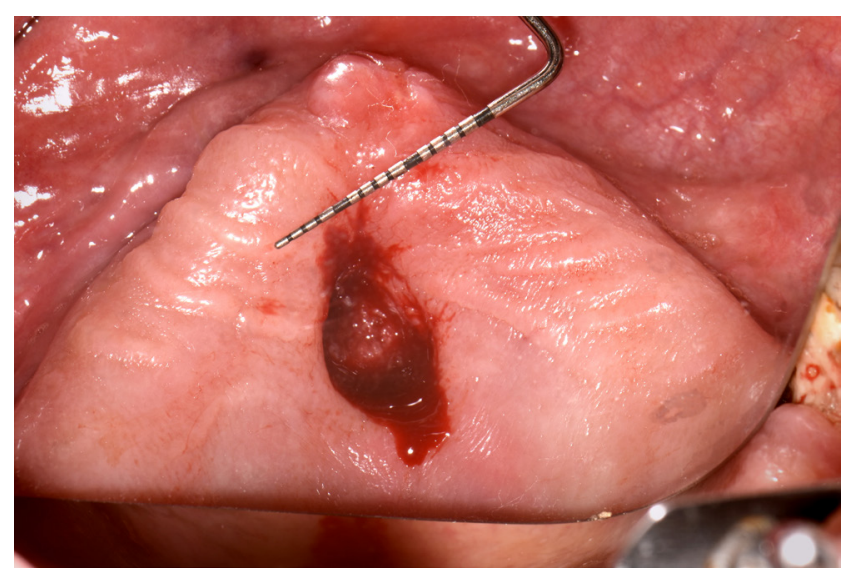

Fig. 2. Excision of the fistula

\section{Pedicled graft}

Two parallel releasing incisions were made from the area of the maxillary tuber to the edge of the fistula. The width of the flap amounted to approx. $1 \mathrm{~cm}$ (Fig. 3). During the preparation of the divided flap, particular attention was paid to the location of the greater palatine foramen and greater palatine artery. The incisions in the distal part of the flap were made at a distance of about $5 \mathrm{~mm}$ from the visible structures (Fig. 4). Then, the greater palatine artery was dissected and the separated connective tissue flap was released, as it was held on the pedicle of this vessel (Fig. 5).

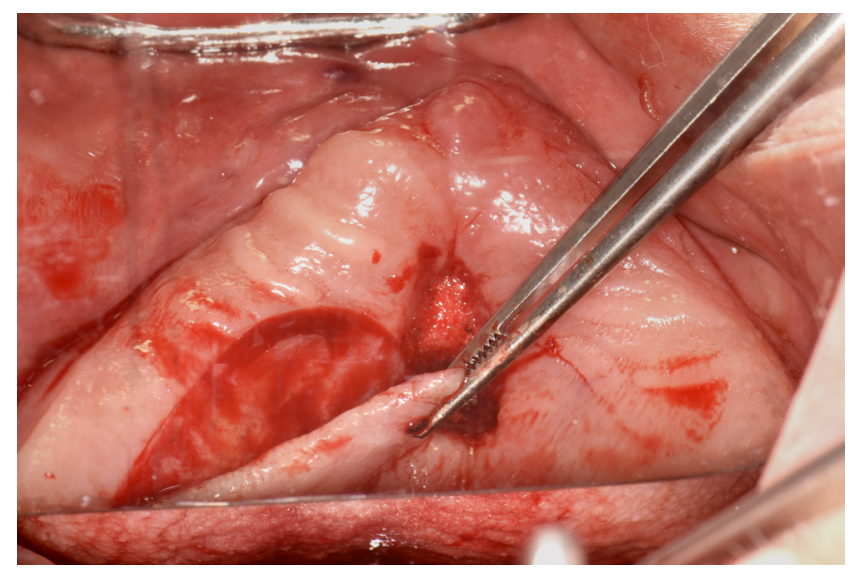

Fig. 3. Preparation of the split flap on the right side 


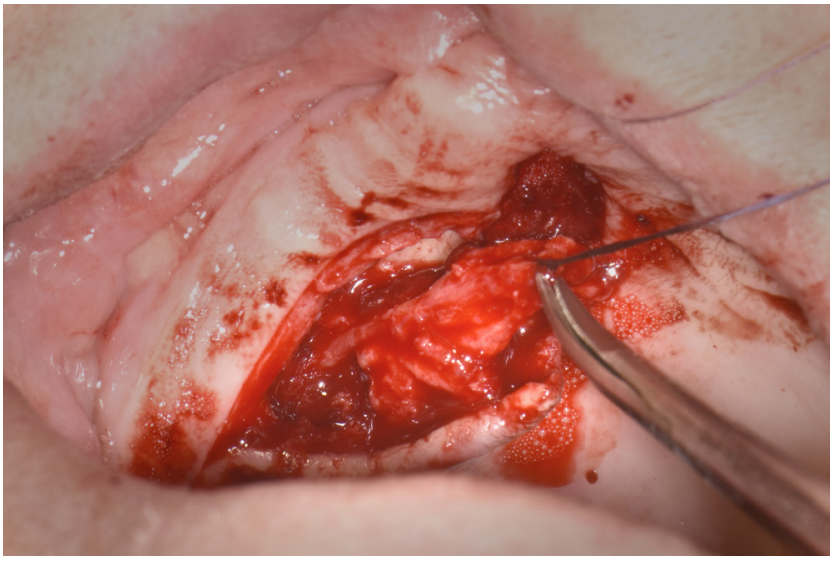

Fig. 4. Preparation of the split flap (visualization of the connective tissue)

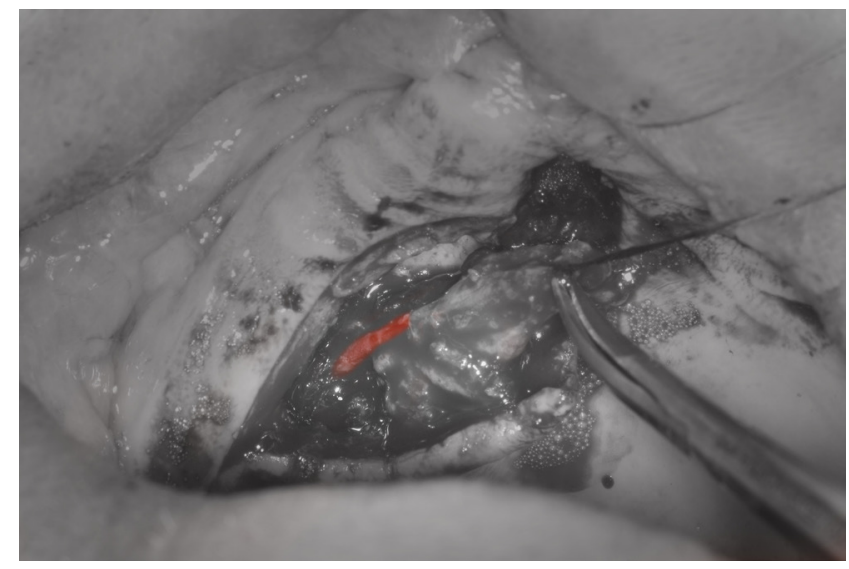

Fig. 5. Visualization of the pedicle made of the greater palatine artery (red)

\section{Tinti-Parma-Benfenati graft}

In the 90s, Tinti and Parma-Benfenati proposed a new technique for the implementation of the split graft. The procedure is based on shifting the tissue flap toward the lesion by performing 2 horizontal incisions, parallel to each other, carried out on 2 levels (on the cross-section resembling the letter Z) (Fig. 6). The more superficial incision is done just below the epithelial layer, from the side of the defect. The deeper incision runs under the connective tissue at the base of the graft. Perpendicular releasing incisions should be executed according to the applicable rules of periodontal surgery. It should be noted that a microsurgical scalpel blade was used for the horizontal releasing incisions (dental spoon blade; MJK Instruments, Marseilles, France), an invaluable advantage of which is the ability to shape the bend (i.e., the blade-bend angle) using pliers, according to the demands of the procedure.

\section{Wound suturing}

The wound was sutured in layers. The pedicle connective tissue flap supplied by the greater palatine artery was moved above the fistula and was stabilized using an absorbable braided suture (3-0 PGLA LACTIC ${ }^{\circledR}$; Yavo Sp. z o.o.,

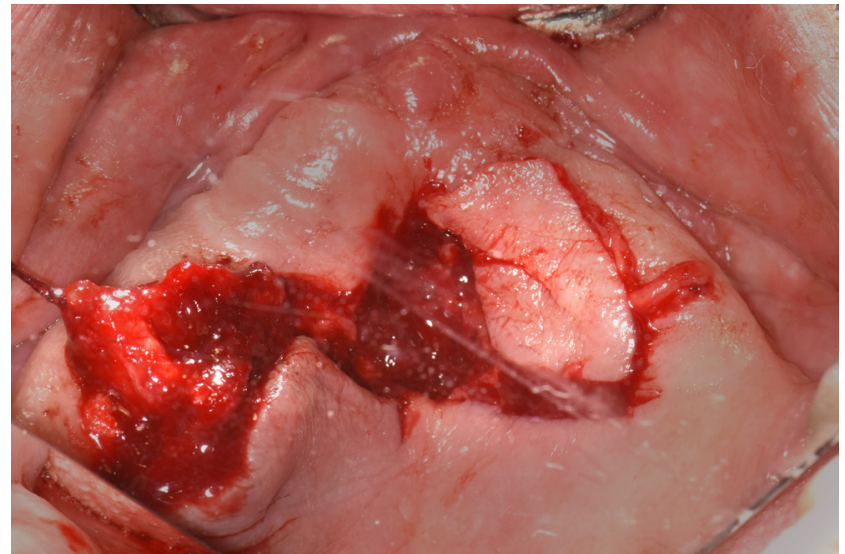

Fig. 6. Preparation of the Tinti-Parma-Benfenati (TPB) flap (right) and the pedicled flap (left)

Bełchatów, Poland). The connective tissue fragment was covered with the Tinti-Parma-Benfenati (TPB) graft shifted from the opposite side. Tight wound closure was achieved using a non-absorbable monofilament suture (5-0 Monosof ${ }^{\mathbb{\mathbb { }}}$; Covidien, Dublin, Ireland). The tissue loss resulting from the displaced TPB flap was supplied tightly with non-absorbable monofilament sutures (5-0 Monosof; Covidien). The remaining wound edges were left for open healing by granulation (Fig. 7).

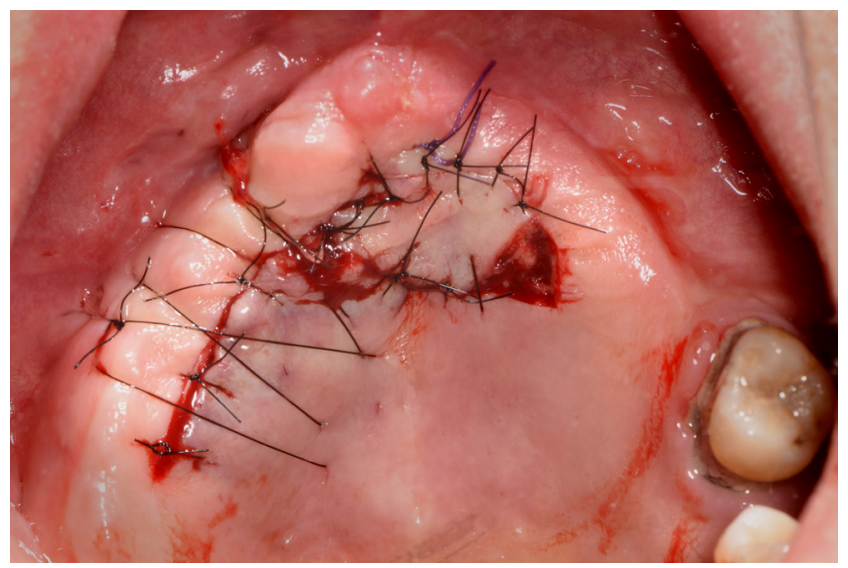

Fig. 7. Wound closure

\section{Healing process}

Complaints of pain subsided 3 days after surgery. The sutures were removed after 2 weeks (Fig. 8).

The use of mouth rinse and gel with chlorhexidine $(0.1 \%$ and $0.2 \%$, respectively) are recommended throughout the healing period according to the manufacturer's instructions. With regard to the tissues not involved in the surgical procedure, the venous return did not show differences noticeable during a clinical examination. The patient did not report any leakage from the nasal passages throughout the follow-up period. In the postoperative period, the discontinuation of the use of the denture was recommended until soft tissues heal and the prosthesis is corrected (Fig. 9,10). 


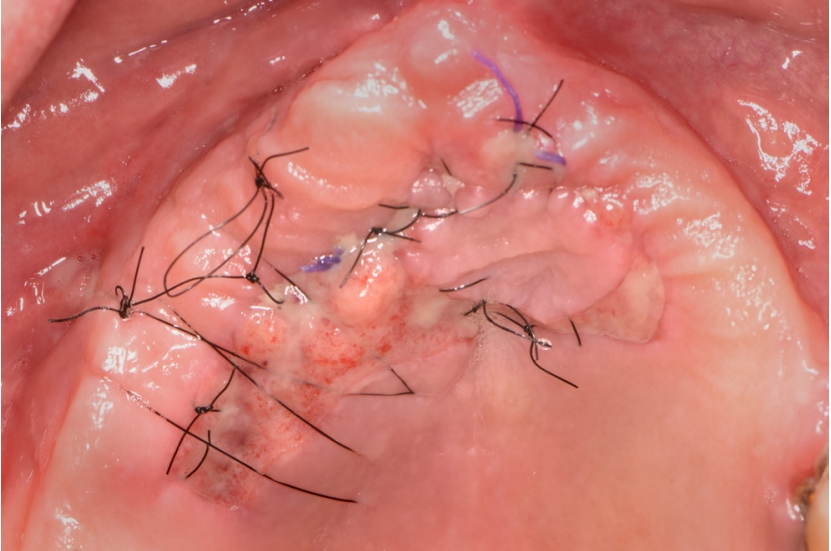

Fig. 8. Status after 2 weeks

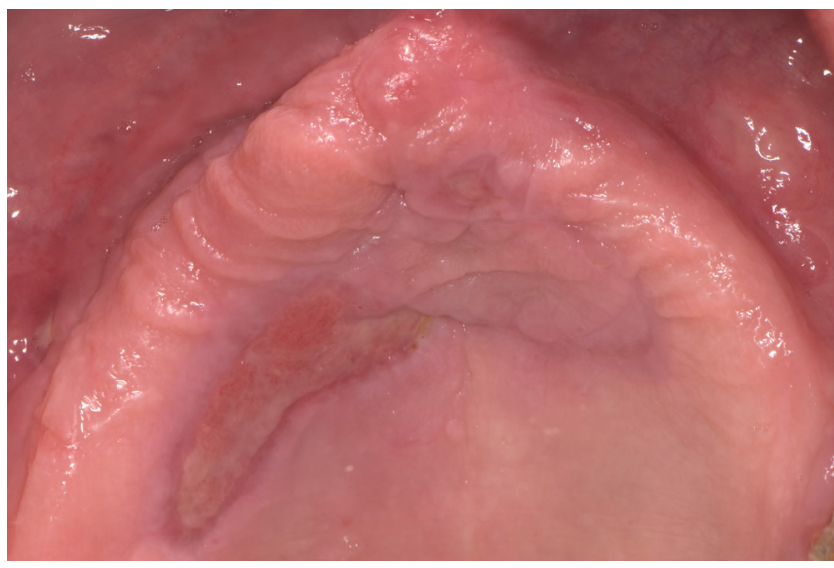

Fig. 9. Status after 3 weeks

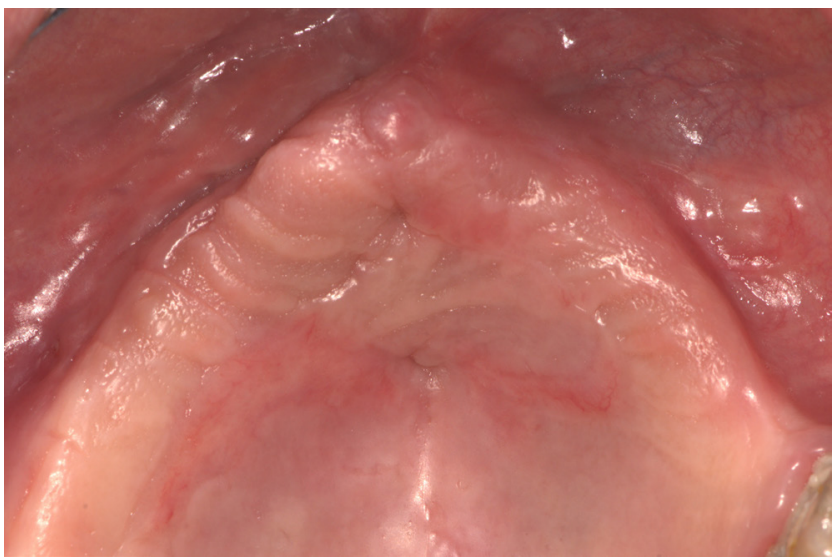

Fig. 10. Wound healing after 6 weeks

The patient was referred to the prosthodontist after surgical treatment. It was necessary to rebase the denture. A follow-up was recommended in June 2019. There were no local complications observed during this period.

The whole procedure is presented in a diagram in Fig. 11. The numbers present the stages of preparation of each layer, respectively. Number 1 presents the $1^{\text {st }}$ preparation of the connective flap, which was moved medially and forward (yellow arrow), whereas number 2 presents the

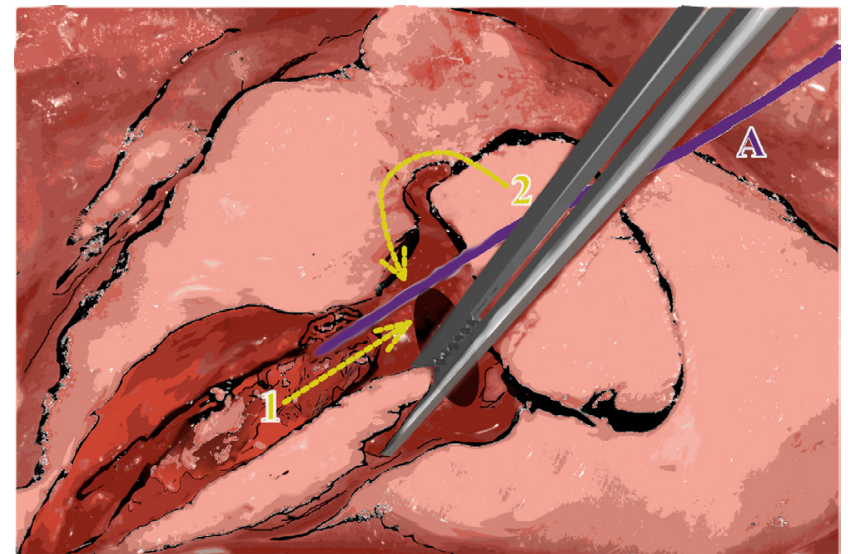

Fig. 11. Scheme of the whole procedure

TPB flap rotated and moved medially, slightly distally (yellow arrow). The violet thread, presented by the letter A, shows the stitch laces used for holding the tissue flap.

\section{Discussion}

Treatment in patients with BRONJ is a complex problem and is focused on covering the denuded bone with soft tissue, simultaneously providing good blood supply. The problem emerges in the literature and is still unsolved. ${ }^{5-8,11}$ An essential aspect of treatment is the proper care of soft tissues. ${ }^{5,6,11}$ Currently, there is a lack of developed methods when it comes to dealing with the complications associated with BP therapy. It has to be emphasized that medication, on the one hand, impairs disease development, but, on the other hand, weakens general health, involving the healing of soft tissues, e.g., the formation of new vessels. A well-known fact is that $\mathrm{N}$-BPs may cause BRONJ development. A good solution seems to be to change the medication and reduce BRONJ expansion. Such treatment is proposed by Oizumi et al., who tried to exchange N-BPs with non-N-BPs. ${ }^{1}$ They proposed a simultaneous surgical intervention to diminish infection and promote healing mechanisms. ${ }^{1}$ What needs to be mentioned is that this kind of treatment is still perspective and needs further evaluation. Minimally invasive therapy also appears in the literature, especially when reconstructive surgery is taken into consideration. Reconstructive surgery is a medical term used to describe the surgical treatment of patients with sophisticated injuries involving various tissues, such as skin, mucosa, muscle, bone, and nerves. Various types of flaps are mentioned in the literature (nasolabial flap, mylohyoid flap, free tissue transfer). Mücke et al. proposed reconstructive surgery by means of a mylohyoid flap. ${ }^{16}$ Despite the fact that this method is rarely used in contemporary reconstructive surgery, it has its advantages, such as the simplicity and predictability of the technique; however, the disadvantages should also be mentioned. 
Neurological damage (to the lingual or alveolar nerve), salivary duct damage, and the shallowing or altering of the muscle attachment can lead to severe problems. Usually, patients with BRONJ are edentulous, and thus a lack of good stabilization of a lower denture (observable quite often) and a lack of sensitivity in the lingual nerve seem to be considerable drawbacks. The choice of this kind of treatment should be thoroughly considered. ${ }^{17}$

The authors of this paper focused on the proper and careful preparation of the soft tissues of the hard palate. One of the well-known methods, and the oldest mentioned in the literature, is reconstruction with a nasolabial flap. This kind of reconstruction is very reliable - flaps are thick enough to provide the proper blood supply and the pedicle is longer, which helps to extend the flap. The thickness of the flap is determined by the reconstruction requirements used for covering small oral defects after tumor excision, resulting in good esthetic and functional effects. ${ }^{13,18}$ Flaps can be used for the regeneration of the intraoral defects of the hard and soft tissues of the maxilla, palate, gingivae, and buccal mucosa, and for the restoration of different parts of the mouth, such as the anterior mouth floor. ${ }^{19}$ A nasolabial flap also has very good blood supply from the adjacent tissues (i.e., dermal and subdermal plexuses as well as facial and transverse facial arteries).${ }^{19}$ Despite indisputable proneness to using this method, it should be approached with caution. It may lead to unwanted inclusion cysts, originating from hair follicles, which may leave unesthetic scars and may expose patients to unnecessary suffering. ${ }^{13,18-20}$ Free tissue transfer - a procedure described by Engroff et al. - seems to be a good alternative. ${ }^{21}$ It has to be mentioned that harvesting the proper soft tissue for the graft results in more wounds, which may lead to scars, and esthetic or various functional problems. ${ }^{21}$ The patient should be carefully examined before any decisions on the specific method are made and the whole case should be thoroughly considered, weighing the pros and cons of each method.

The authors of various publications on the surgical methods of closing the defects with surrounding soft tissue grafts, or with the use of synthetic materials and materials of animal origin are much too critical of exact and tight wound closure. ${ }^{5,6,11,22}$ Due to the unpredictability of the vascular blood supply, the proposed methods do not guarantee repeatable satisfactory outcomes. The above procedure is one of the possible methods that can be used while retaining the generally accepted principles of surgical treatment. It should be emphasized that the occurrence of sequestra often eliminates the possibility of using surrounding soft tissue flaps, given the difficulties in covering the developed bone defect. ${ }^{11}$

It is vital that the patient diligently follows the instructions given by the medical personnel, including ceasing BP therapy after consulting the attending physician. In the present study, throughout the entire convalescence period, the patient abided by the recommendations, being aware of his participation in the healing process.

Despite a complication in the initial procedure (i.e., the removal of the sequestrum), the described surgical technique allows the lasting closure of an oronasal fistula and can be recommended in the treatment of similar cases. In the context of blood circulation disorders caused by BP therapy, the maintenance of the vascular pedicle of the graft contributed to proper healing. Thus, the protection of the site against further trauma, the usage of topical chlorhexidine and antibiotic therapy play a crucial supportive role in recovery. Laser therapy and extracorporeal shockwave therapy (ESWT) are mentioned as intensifying healing. ${ }^{7,17,23}$ Low-level laser therapy (LLLT) is a widely known method of improving and accelerating the healing of various types of tissues. This method uses low-energy light to increase the production of mitochondrial enzymes, porphyrins, flavins, and cytochromes. Adequately to the region of the body and the type of laser used, the light is absorbed by cells and - by means of a still unclear mechanism - leads to good tissue healing. ${ }^{17}$ While LLLT is considered to be non-invasive, ESWT is based on causing damage by means of an externally applied, focused, high-intensity acoustic pulse. A shockwave is an acoustic wave which carries high energy to painful spots and myoskeletal tissues. It is characterized by a jump change in pressure, high amplitude and non-periodicity. This energy is produced by compressed air and is transferred to the transmitter at the end of the applicator, and further into the tissue. Before commencing the procedure, patients are usually sedated or anesthetized in order to help them remain still and to reduce possible discomfort. The exact mechanism of ESWT remains unknown. ${ }^{23}$ It has been proven that acoustic waves create micro-ruptures in the bone, which significantly increase the expression of such growth factors as BMPs and vascular endothelial growth factor (VEGF). ${ }^{24}$ There is another method successfully used by many doctors to increase the expression of growth factors (e.g., plateletderived growth factor - PDGF). It uses peripheral blood for preparing a clot (here named platelet-rich fibrin - PRF) by centrifugation; thus, the platelets and their crucial factors are concentrated for healing acceleration. The procedure was invented and introduced by Joseph Choukroun. ${ }^{\text {acc.24 }}$ Such prepared PRF may be used for closing wounds and accelerating healing - a layer is placed directly on the denuded bone, and is then covered by the tissue sutured without pressure. ${ }^{25}$ We can find various techniques used for regeneration that utilize PRF. The techniques of surgery, tissue engineering and bone biology are merged to offer promising solutions. ${ }^{24,26}$

All the procedures performed in the present study were carried out in accordance with the ethical standards of the institutional and national research committee, and with the 1964 Declaration of Helsinki and its later amendments, or comparable ethical standards. 


\section{ORCID iDs}

Piotr Radziszewski (iD https://orcid.org/0000-0001-9139-9122

Maciej Włodarczyk (D) https://orcid.org/0000-0002-8628-0773

Ivan Yafimtsau (D) https://orcid.org/0000-0003-1008-7667

\section{References}

1. Oizumi T, Yamaguchi K, Sato K, et al. A strategy against the osteonecrosis of the jaw associated with nitrogen-containing bisphosphonates (N-BPs): Attempts to replace N-BPs with the Non-N-BP etidronate. Biol Pharm Bull. 2016;39(9):1549-1554.

2. Arundel P. Osteogenesis imperfecta. Paediatr Child Health. 2015;25(12):574-579.

3. Patel V, Kelleher M, Sproat C, Kwok J, McGurk M. New cancer therapies and jaw necrosis. Br Dent J. 2015;219(5):203-207.

4. Winnie Zee Man Wat. Current perspectives on bisphosphonate treatment in Paget's disease of bone. Ther Clin Risk Manag. 2014;10:977.

5. Otto S, Schreyer C, Hafner S, et al. Bisphosphonate-related osteonecrosis of the jaws - characteristics, risk factors, clinical features, localization and impact on oncological treatment. J Craniomaxillofac Surg. 2012;40(4):303-309.

6. Ruggiero SL, Dodson TB, Fantasia J, et al. American Association of Oral and Maxillofacial Surgeons position paper on medicationrelated osteonecrosis of the jaw - 2014 update. J Oral Maxillofac Surg. 2014;72(10):1938-1956.

7. Marx RE, Sawatari Y, Fortin M, Broumand V. Bisphosphonateinduced exposed bone (osteonecrosis/osteopetrosis) of the jaws: Risk factors, recognition, prevention, and treatment. J Oral Maxillofac Surg. 2005;63(11):1567-1575.

8. Kumar V, Shahi AK. Nitrogen containing bisphosphonates associated osteonecrosis of the jaws: A review for past 10 year literature. Dent Res J (Isfahan). 2014;11(2):147-153.

9. https://www.cancerresearchuk.org/. Accessed February 1, 2002.

10. Engroff SL, Coletti D. Bisphosphonate related osteonecrosis of the palate: Report of a case managed with free tissue transfer. Oral Surg Oral Med Oral Pathol Oral Radiol Endod. 2008;105(5):580-582.

11. Comas-Calonge A, Figueiredo R, Gay-Escoda C. Surgical treatment vs. conservative treatment in intravenous bisphosphonate-related osteonecrosis of the jaws. Systematic review. J Clin Exp Dent. 2017;9(2):e302-e307.

12. Vermeer JAF, Renders GAP, Everts V. Osteonecrosis of the jaw - a bone site-specific effect of bisphosphonates. Curr Osteoporos Rep. 2016;14(5):219-225.

13. Eleutherakis-Papaiakovou V. Thalidomide in cancer medicine. Ann Oncol. 2004;15(8):1151-1160.

14. Larsen PE, ed. Part 3: Maxillofacial Infections. In: Miloro M, Ghali GE, Larsen PE, Waite PD, eds. Peterson's Principles of Oral and Maxillofacial Surgery. $2^{\text {nd }}$ ed. Hamilton, Canada: BC Decker Inc.; 2004:276-232.

15. Dreppe $H$, Eskici $A$, Herzog $M$, et al. Science about specialized infections. In: Horch HH, ed.; Kryst L, ed. (Polish edition). Oral Surgery [in Polish]. Wrocław, Poland: Urban \& Partner;1997:117-161.

16. Mücke T, Koerdt S, Jung M, et al. The role of mylohyoid flap in the treatment of bisphosphonate-related osteonecrosis of the jaws. J Craniomaxillofac Surg. 2016;44(4):369-373.

17. Luomanen M, Alaluusua $S$. Treatment of bisphosphonate-induced osteonecrosis of the jaws with Nd:YAG laser biostimulation. Lasers Med Sci. 2012;27(1):251-255.

18. Rahpeyma A, Khajehahmadi S. The place of nasolabial flap in orofacial reconstruction: A review. Ann Med Surg (Lond). 2016;12:79-87.

19. Singh S, Singh RK, Pandey M. Nasolabial flap reconstruction in oral cancer. World J Surg Oncol. 2012;10:227.

20. Alonso-Rodríguez E, Cebrián-Carretero JL, Morán-Soto MJ, BurgueñoGarcia M. Versatility of nasolabial flaps in oral cavity reconstructions. Med Oral Patol Oral Cir Bucal. 2014;19(5):e525-e530.

21. Ruggiero SL, Mehrotra B, Rosenberg TJ, Engroff SL. Osteonecrosis of the jaws associated with the use of bisphosphonates: A review of 63 cases. J Oral Maxillofac Surg. 2004;62(5):527-534.

22. Zuhr O, Hürzeler MB. Primary healing: The key to success. In: Zuhr O, Hürzeler MB. Plastic-Esthetic Periodontal and Implant Surgery: A Microsurgical Approach. London, UK: Quintessence Publishing; 2012:68-83.
23. Wang CJ, Wang FS, Yang KD, et al. Treatment of osteonecrosis of the hip: Comparison of extracorporeal shockwave with shockwave and alendronate. Arch Orthop Trauma Surg. 2008;128(9):901-908.

24. Tsai LL, Huang YF, Chang YC. Treatment of bisphosphonate-related osteonecrosis of the jaw with platelet-rich fibrin. J Formos Med Assoc. 2016;115(7):585-586.

25. Wang CJ, Wang FS, Yang KD. Biological mechanism of musculoskeletal shockwaves. ISMST Newsletter. 2006;1(1):5-11.

26. Liao HT, Chen CT, Chen CH, Chen JP, Tsai JC. Combination of guided osteogenesis with autologous platelet-rich fibrin glue and mesenchymal stem cell for mandibular reconstruction. J Trauma. 2011;70(1):228-237. 